\title{
UM NOVO GÊNERO E NOVAS ESPÉCIES DE PENTATOMINI DO BRASIL (HETEROPTERA, PENTATOMIDAE)
}

\author{
Nora Denise Fortes de Fortes ${ }^{1,2}$ \\ Jocélia Grazia ${ }^{1,3}$
}

\begin{abstract}
A new genus And new SPeCies of Pentatomini from Brazil (Heteroptera, Pentatomidae). A new genus, Similliserdia gen.n. and two new species, $S$. aciculata sp.n. (from Santa Catarina) and S. quadriarticulata sp.n. from (from Acre) are described. A study of the morphology of the genitalia is included.

KEY WORDS. Heteroptera, Pentatomini, Similliserdia, taxonomy, morphology of genitalia
\end{abstract}

O gênero Similliserdia faz parte da seção 3 da tribo Pentatomini, proposto por RoLSTON et al. (1980), que reúne os gêneros que possuem um espinho mediano na base ventral do abdome, em aposição à carena do metasterno. Numa análise cladística preliminar, constatou-se uma estreita relação de parentesco entre Similliserdia e os gêneros Neotibilis, Tibilis, Serdia e um novo gênero a ser proposto (FORTES in litt.).

Todos os exemplares foram medidos; as medidas estão expressas em milímetros. Por se tratarem de exemplares únicos, não foram dissecados o pigóforo de $S$. aciculata e a fêmea de $S$. quadriarticulata, para o estudo da genitália interna. A nomenclatura das peças da genitália seguiu DuPUIS $(1955,1970)$.

As espécies estudadas provêm das seguintes coleções: (AMNH) American Museum of Natural History, New York, USA; (MPEG) Museu Paraense Emílio Goeldi, Belém, Pará, Brasil; (MZSP) Museu de Zoologia, Universidade de São Paulo, São Paulo, Brasil; e (UFRG) Departamento de Zoologia, Universidade Federal do Rio Grande do Sul, Porto Alegre, Brasil.

\section{Similliserdia gen.n.}

Fig. 1

Espécie-tipo. Similliserdia aciculata sp.n.

Tamanho médio, corpo arredondado, moderadamente convexo tanto dorsal quanto ventralmente. Superfície dorsal pontuada e superfície ventral com pontuações menos densas do que no dorso.

1) Departamento de Zoologia, Instituto de Biociências, Universidade Federal do Rio Grande do Sul. Avenida Paulo Gama, 90046-900 Porto Alegre, Rio Grande do Sul, Brasil.

E-mail: jocelia@vortex.ufrgs.br ou noraento@vortex.ufrgs.br

2) Bolsista de Doutorado, CAPES.

3) Bolsista CNPq. 


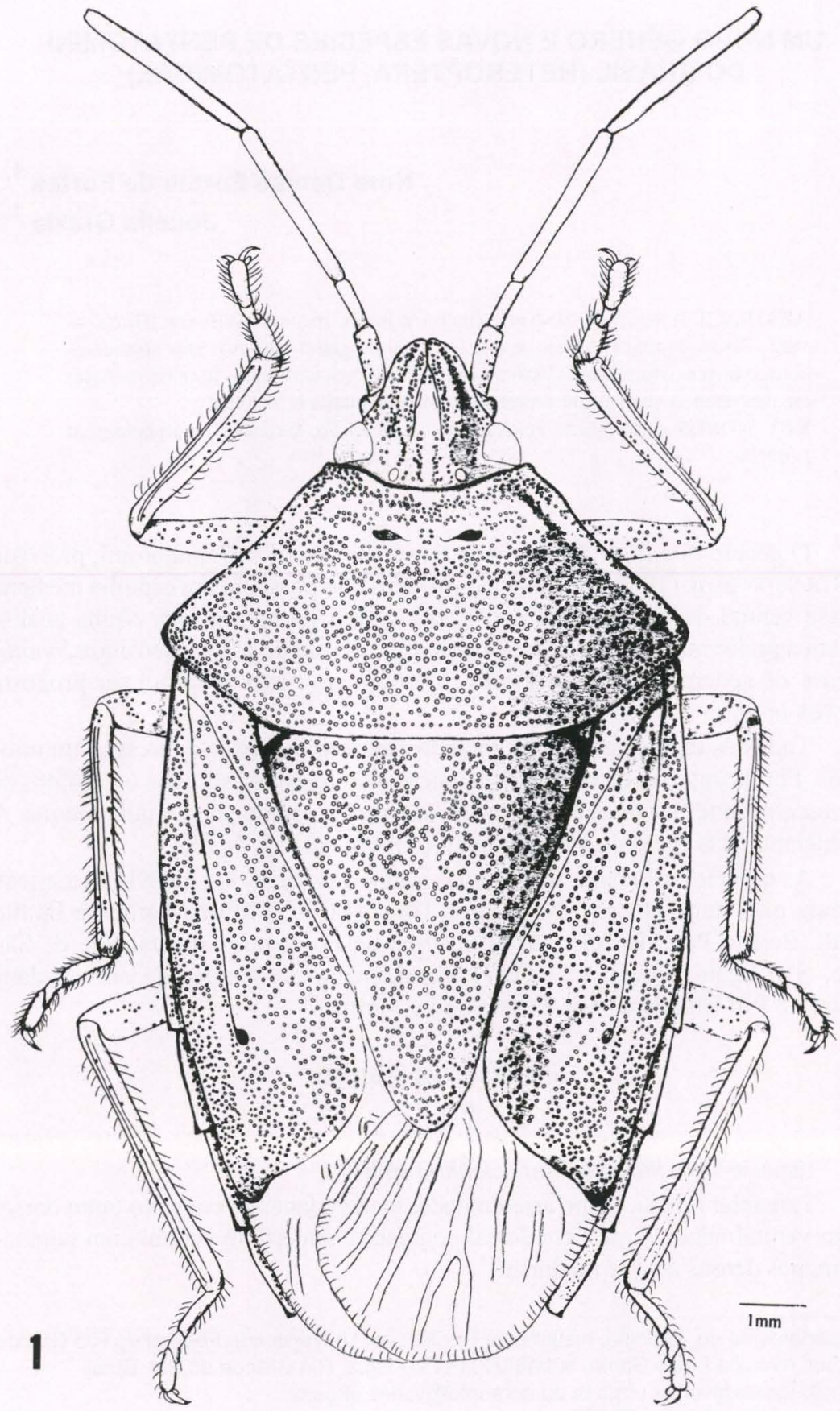

Fig. 1. Similliserdia aciculata sp.n., holótipo macho. 
Cabeça. Comprimento maior que a metade do comprimento do pronoto. Largura ao nível dos olhos não ultrapassando a margem anterior do pronoto. Cabeça e 2/3 anteriores do pronoto decliventes. Jugas mais longas que o clípeo, justapostas no ápice, margens laterais subretilíneas. Tubérculo antenífero visível dorsalmente. Búculas curtas, moderadamente elevadas, evanescentes posteriormente; margens subretilíneas, anteriormente em ângulo reto. Primeiro segmento rostral contido inteiramente nas búculas; segundo segmento menor que o terceiro e quarto reunidos.

Pronoto subtrapezoidal, duas vezes mais largo ao nível dos úmeros que longo medianamente. Margem anterior côncava, margens ântero-laterais íntegras, emarginadas, e subretilíneas; projeção dos ângulos ântero-laterais pouco desenvolvida, com ponta romba e lateralmente dirigida. Margens póstero-laterais e posteriores subretilíneas. Ângulos umerais quase retos.

Escutelo triangular, mais longo que largo na base; disco mais elevado; margem basal com $1+1$ pequenas fóveas negras. Ápice moderadamente agudo, quase alcançando a linha imaginária transversal que une os ápices do quinto segmento do conexivo.

Hemiélitros. Cório mais longo que o escutelo, ângulos apicais agudos, não alcançando a margem posterior do sexto segmento abdominal. Extremidade posterior da veia radial com uma pequena célula discal negra acompanhada por um pequeno calo amarelado. Membrana escurecida com sete a oito nervuras longitudinais subparalelas, ocasionalmente bifurcadas; sutura da membrana levemente sinuosa.

Conexivo. Em geral, com o terço lateral externo exposto, superfície densa e uniformemente pontuada. Ângulos póstero-laterais com um minúsculo espinho negro.

Mesosterno sulcado e destituído de carena. Áreas evaporatórias mesopleurais percorrendo uma faixa irregular que ocupa um pouco mais do $1 / 3$ basal da mesopleura, ampliando-se em direção as margens laterais. Metasterno em carena pentagonal uniformemente elevada; margem anterior em projeção aguda e lateralmente achatada sobre a base da mesopleura; margem posterior fortemente escavada para encaixe do tubérculo abdominal. Área evaporatória metapleural ocupando 2/3 internos do anepisterno, terminando abruptamente numa prega longitudinal. Peritrema ostiolar curto e auricular.

Abdome, ventralmente, com pontuações castanhas a castanho-escuras, mais densas numa faixa longitudinal larga acompanhando os espiráculos, na margem externa a esta faixa longitudinal as pontuações são menores e menos densas. Na margem interna da faixa longitudinal as pontuações são maiores e mais dispersas. Tubérculo abdominal do terceiro segmento agudo. Espiráculos arredondados, negros internamente.

Pernas. Tíbias cilíndricas e largamente sulcadas.

Genitália do macho. Pigóforo de contorno quadrangular, moderadamente aberto dorso-posteriormente. Sensilas basicônicas recobrindo a superfície interna do bordo dorsal e ângulos póstero-laterais ou restritas somente aos ângulos. Folheto interno do bordo ventral com $1+1$ intumescências na superfície interna, ao nível dos 
parâmeros, e recoberto por longas cerdas que continuam em direção aos ângulos póstero-laterais. Décimo segmento ovalado e marginado de pêlos. Phallus com aparelho articular amplo em relação a phallotheca; vesica apresentando processos, conjuntiva ausente.

Genitália da fêmea. Esternito VII com margem posterior côncava e semicircular sobre os gonocoxitos 8 . Laterotergitos 8 dispostos num plano longitudinal mais elevado em relação aos laterotergitos 9; espiráculos presentes. Gonocoxitos 9 fusionados medianamente formando o pseudoesternito. Décimo segmento retangular.

Comentários. O gênero Similliserdia aproxima-se dos gêneros Serdia Stål, 1860; Tibilis Stål, 1860 e Neotibilis Grazia \& Barcellos, 1994, pelo facies; separa-se essencialmente pelo mesosterno sulcado, terço anterior da carena metasternal afilada e presença de sensilas basicônicas no pigóforo.

\section{Similliserdia aciculata sp.n.}

Figs 1-3, 6-10

Medidas. Machos/Fêmea. Comprimento total, até o ápice do sétimo segmento, em vista dorsal $14,8(14,6-15,0) / 9,1$; comprimento da cabeça $2,5 / 2,4$; largura da cabeça ao nível dos olhos $2,8(2,7-3,0) / 2,7$; comprimento dos artículos antenais: I- $1,0(0,9-1,1) / 1,1 ;$ II- $0,8(0,8-0,9) / 0,7$; III- $2,5(2,4-2,6) / 1,1 ;$ IV-2,9 $(2,9-3,0) / 3,8$; V- falta/1,1; comprimento do pronoto $3,6(3,5-3,8) / 3,5$; largura anterior do pronoto no limite anterior aos dentículos do ângulo ântero-apical 3,03 (3,0-3,1)/3,0; largura do pronoto ao nível dos ângulos umerais $7,7 / 7,6$; comprimento do escutelo 5,9 $(5,9-6,0) / 6,2 ;$ largura basal do escutelo $4,7(4,7-4,8) / 4,9 ;$ largura abdominal ao nível do terceiro segmento $7,6(7,4-7,8) / 7,9$.

Coloração castanho-clara a amarelada; pontuações castanho-escuras levemente menores na cabeça e terço anterior do pronoto e maiores no restante do corpo. Cabeça com pontuações castanho-escuras, moderadamente densas formando $2+2$ linhas longitudinais subparalelas desde a base da cabeça, entre os ocelos, até o ápice das jugas. Metade basal do clípeo com $1+1$ linhas negras convergindo posteriormente. Ventralmente com pontuações mais dispersas, algumas mais grosseiras; uma linha de pontuações menores ao longo da base das búculas. Antenas com cinco artículos de coloração castanho-clara; primeiro segmento antenal nitidamente ultrapassando o ápice da cabeça e subigual ao segundo segmento antenal, este aproximadamente um terço do terceiro segmento; quinto segmento falta. Rostro mal alcançando as coxas médias. Pronoto castanho-claro a amarelado, pontuações castanho-escuras uniformemente distribuídas e de tamanho menor na margem anterior e em torno das cicatrizes. Margens ântero-laterais do pronoto com uma linha de pontuações submarginais seguida de linha subcalosa, destituída de pontuação ao longo dos $2 / 3$ posteriores. Cicatrizes com $1+1$ pequenas manchas enegrecidas próximas às margens laterais internas. Superfície do escutelo com densa pontuação castanho-escura; pontuações menores no disco e no ápice. Hemiélitros com pontuações em série formando duas linhas externas à veia radial intercaladas por uma linha subcalosa destituída de pontuação, esta última alcançando a sutura da mem- 
brana, bifurcando-se ao nível da célula discal. Exocório com pontuações menores, margem externa imaculada. Propleura com linhas de pontuações que margeiam o episterno e o epimero e contorna as cicatrizes. Mesopleura com uma linha mediana transversal de pontuações; demais pontuações da mesopleura e metapleura esparsas. Tricobótrios externos à linha que tangencia externamente os espiráculos. Pernas moderadamente pontuadas, pontuações castanhas, grosseiras nos fêmures, menos densas nas tíbias.
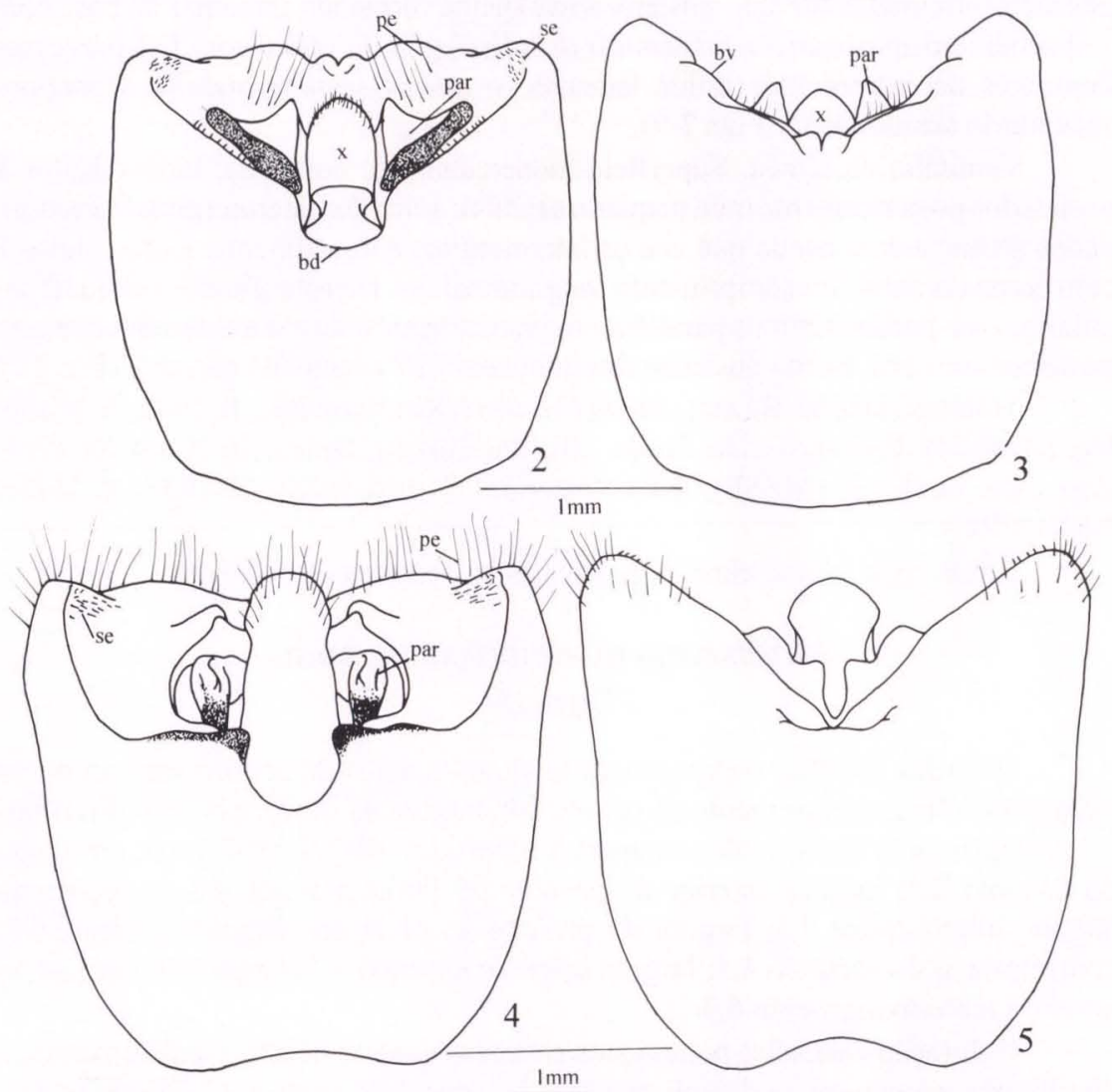

Figs 2-5. Pigóforos. (2-3) Similliserdia aciculata sp.n., vista dorsal e ventral respectivamente; (4-5) S. quadriarticulata sp.n., vista dorsal e ventral respectivamente. (bd) Bordo dorsal, (bv) bordo ventral, (par) parâmero, (pe) pêlos, (se) sensilas, (x) décimo segmento.

Genitália do macho. Pigóforo com ângulos póstero-laterais arredondados e estreitos; bordo dorsal escavado medianamente em pequeno "U" aberto ao nível do décimo segmento; superfície interna do bordo recoberto por inúmeras sensilas basicônicas desde a escavação mediana até os ângulos póstero-laterais (Figs 2, 3). Bordo ventral sinuosamente escavado em "V"; região mediana bifurcada em 1+1 pequenas abas e próximas entre si (Fig. 3); folheto interno pouco desenvolvido, 
sinuoso, não visível em vista ventral. Cabeça do parâmero, em vista dorsal, tripartida, sendo duas projeções posteriores e uma anterior; projeção posterior interna tuberculada, projeções posterior externa e anterior digitiformes; superfície dorsal do parâmero rugosa entre as projeções anterior e posterior externa (Fig. 6). Phallus: com conectivos dorsais espessos, processus capitati arredondados e quase atingindo o ápice da phallotheca. Phallotheca arredondada e curvando-se fortemente para o lado dorsal; ápice com $1+1$ expansões cônicas. Vésica em forma de um longo pescoço fortemente curvado póstero-dorsalmente formando um anel; na base com $1+1$ tubérculo aposto ao ductus seminis distalis. Ápice da vésica com $1+1$ processos laminares de extremidade bífida ladeando o ductus seminis distalis. Gonoporo secundário arredondado (Figs 7-9).

Genitália da fêmea. Superficie moderadamente pontuada; laterotergitos 8 projetados posteriormente num pequeno espinho; ápice dos laterotergitos 9 arredondados alcançando a banda que une os laterotergitos 8 dorsalmente. Gonocoxitos 8 com cerca do dobro do comprimento longitudinal dos laterotergitos 9 , subquadrangulares, com bordos suturais paralelos em praticamente toda a sua extensão, margem posterior convexa. Bordo posterior dos gonocoxitos 9 rasamente côncavo (Fig. 10).

Holótipo macho. BRASIL, Santa Catarina: Rio Vermelho, II-1945, A. Maller leg. (AMNH). Parátipos. São Paulo: Ilha dos Búzios, fêmea, 16-X a 4-XI-1963, Exp. Dep. Zool. leg. (MZSP); Santa Catarina: Corupá, macho X-1953, A. Maller leg. (UFRG).

Etimologia. Nome alusivo às sensilas basicônicas do pigóforo.

\section{Similliserdia quadriarticulata sp.n.}

Figs 4,5

Medidas. Macho: comprimento total, até o ápice do sétimo segmento, em vista dorsal 10,5; comprimento da cabeça 2,0 ; largura da cabeça ao nível dos olhos 2,1; comprimento dos artículos antenais: I-0,9; II-3,6; III-3,0; IV-2,7; comprimento do pronoto 2,6; largura anterior do pronoto no limite anterior das projeções do ângulo ântero-apical 2,3; largura do pronoto ao nível dos ângulos umerais 6,0 ; comprimento do escutelo 4,5; largura basal do escutelo 3,5; largura abdominal ao nível do terceiro segmento 6,3.

Coloração castanha; pontuações castanho-escuras densas e uniformemente distribuídas na superfície dorsal; menores na superfície ventral. Cabeça com $1+1$ linhas semi-circulares de pontuações castanho-escuras no terço médio-basal da cabeça. Ventralmente, pontuações moderadamente densas e grosseiras. Antenas com quatro artículos, castanho-avermelhados; primeiro segmento antenal nitidamente ultrapassando o ápice da cabeça, segundo segmento antenal com mais de seis vezes o comprimento do primeiro artículo. Rostro ultrapassando as coxas médias. Pronoto de coloração castanha, pontuações castanho-escuras uniformemente distribuídas exceto nas margens ântero-laterais, onde são maiores e mais grosseiras. Escutelo com pontuações menores no terço apical. Hemiélitros com pontuações menores no exocório; pontuações maiores e mais grosseiras ao longo da margem externa. Pro, meso e metapleura com pontuações castanho-escuras, moderadamente 
densas no episterno e no epimero; mais esparsas no restante. Abdome, ventral: tricobótrios situados um de cada lado da linha longitudinal imaginária tangente aos espiráculos. Pernas castanho-amareladas, moderadamente pontuadas, pontuações castanhas, grosseiras nos fêmures e até a metade apical das tíbias; tarsos avermelhados.

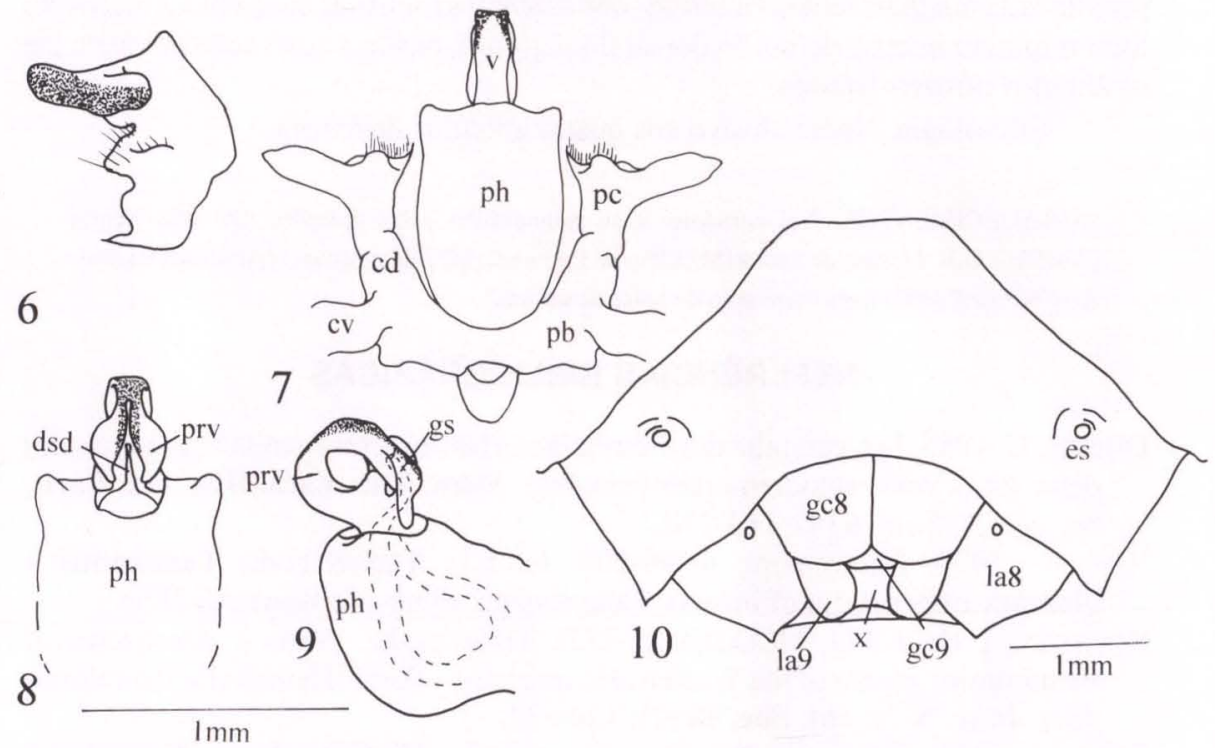

Figs 6-10. Similliserdia aciculata sp.n.. (6) Parâmero, vista lateral interna; (7-9) phallus, vista ventral, dorsal (sem a placa basal) e lateral respectivamente; (10) placas genitais da fêmea, vista ventral. (cd) Conectivos dorsais, (cv) conectivos ventrais, (dsd) ductus seminis distalis, (es) espiráculo, (gc8) gonocoxito 8 , (gc9) gonocoxito 9 , (gs) gonoporo secundário, (la8) laterotergito 8, (la9) laterotergito 9, (pb) placa basal, (pc) processus capitati, (ph) phallotheca, (prv) processo da vésica, $(v)$ vésica, $(x)$ décimo segmento.

Genitália do macho. Pigóforo com ângulos póstero-laterais arredondados; taça genital ampla; bordo dorsal bissinuoso, escavado medianamente em pequeno "U" aberto ao nível do décimo segmento; terço mediano do bordo, de cada lado da escavação em "U", enegrecido. Sensilas basicônicas restritas aos ângulos pósterolaterais (Fig. 4). Bordo ventral sinuosamente escavado em "V"; folheto interno do bordo bem desenvolvido, bissinuoso, profundamente escavado em "U" estreito no meio (Fig. 5). Parâmeros subcilíndricos, cabeça mais estreita, subespatulada, dobrada em gancho em direção anterior, superfície apical rugosa; em vista dorsal, ângulo apical interno projetando-se em pequeno dente, parcialmente encoberto pelo bordo dorsal (Fig. 4).

Holótipo macho. BRAsIL, Acre: Rio Branco, 25-X a 8-XI-91, F. Ramos, A. Henrique, I. Gorayeb \& N. Bittencourt leg. (MPEG).

Diagnose diferencial. S. quadriarticulata se diferencia de S. aciculata por apresentar quatro artículos antenais, margens ântero-laterais do pronoto e margens 
externas do exocório com pontuações maiores e mais grosseiras e destituída de linha subcalosa; nos machos, as sensilas basicônicas do pigóforo restringem-se aos ângulos póstero-laterais. $S$. aciculata se distingue por apresentar cinco artículos antenais; margens ântero-laterais do pronoto e margens externas do exocorio com uma linha subcalosa destituída de pontuação; cicatrizes com $1+1$ pequenas manchas próximas às margens laterais internas; nos machos, as sensilas basicônicas recobrem todo o folheto interno do bordo dorsal do pigóforo, desde a escavação mediana até os ângulos póstero-laterais.

Etimologia. Nome alusivo aos quatro artículos da antena.

AGRADECIMENTOS. Aos curadores e/ou responsáveis pelas coleções: Dr. R.T. Schuh (AMNH); U.R. Martins de Souza (MZSP) e W.L. Overal (MPEG) pelo empréstimo de material. Ao CNPq e CAPES pela concessão de bolsa às autoras.

\section{REFERÊNCIAS BIBLIOGRÁFICAS}

DupuIs, C. 1955. Les genitalia des Hémiptères-Hétéroptères (genitalia externes des deux sexes voies ectodermiques femelles). Mém. Mus. natn. Hist. nat. Paris, n.s. sér. A. Zool, 6 (4): 183-278.

- 1970. Heteroptera, p.190-208. In: S.L. TUXEN (Ed.) Taxonomist's glossary of genitalia of insects. Copenhagen, Ejnar-Munksgaard, 285p.

Rolston, L.H.; F.J.D. MCDONALD; D.B. Thomas JR. 1980. A conspectus of Pentatomini genera of the Western Hemisphere - Part I (Hemiptera: Pentatomidae). Jour. N. Y. ent. Soc. 88 (2): 120-132.

STÅL, C. 1860. Bidrag till Rio Janeiro - traktens Hemipter-fauna. K. svenska Vetenskakad. Handl. 2 (7): 1-84.

Recebido em 12.IX.1997; aceito em 26.X.1998. 